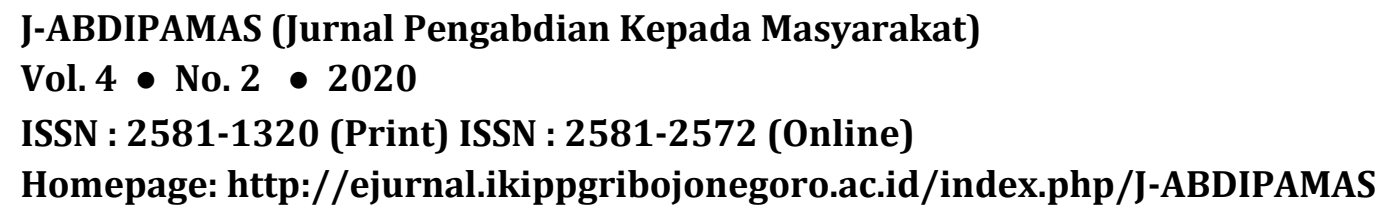

\title{
Sosialisai Aplikasi Hello English Kids kepada Ibu PKK RW 10 Kampung Tengah
}

\author{
Ria Saraswati ${ }^{1}$, Tiarma Ika Yuliana ${ }^{2}$ \\ ${ }^{1}$ Universitas Indraprasta PGRI. Email: riri.saraswati21@gmail.com \\ 2 Universitas Indraprasta PGRI. Email: tiarmaika@gmail.com
}

\begin{abstract}
The learning process especially for learning English will be more fun, not boring and easy to understand for children if it uses the right learning media which can foster children's reading and writing abilities. Learning media is a tool that serves to convey learning messages. Media in learning has a function as a tool to clarify the message conveyed by the teacher. The media also functions for individual learning where the position of the media fully serves the learning needs of students. Multimedia is one source of teaching or alternative media in learning English that can integrate and link elements of the human physical environment in the dimensions of space. It predicts one of the interactive multimedia learning that to improve children's reading and writing abilities is the learning media in a mobile phone application called Hello English Kids: Learn English. Hello English Kids Media: Learn English predicted to improve children's reading and writing skills because this media teaches English to children in a fun, effective way and can build a strong foundation for their language development so it can attract attention, curiosity, arouse enthusiasm and fun for children.
\end{abstract}

Keywords: reading, writing, multimedia

\begin{abstract}
ABSTRAK
Proses pembelajaran khususnya untuk pembelajaran Bahasa Inggris akan lebih menyenangkan, tidak membosankan dan lebih mudah dipahami anak jika menggunakan media pembelajaran yang tepat yaitu media yang dapat menumbuhkan kemampuan membaca dan menulis anak. Media pembelajaran adalah sebuah alat yang berfungsi untuk menyampaikan pesan pembelajaran. Media dalam pembelajaran memiliki fungsi sebagai alat bantu untuk memperjelas pesan yang disampaikan guru. Media juga berfungsi untuk pembelajaran individual di mana kedudukan media sepenuhnya melayani kebutuhan belajar siswa. Multimedia adalah salah satu sumber pengajaran atau media alternatif dalam pembelajaran Bahasa Inggris yang dapat memadukan dan mengaitkan unsur lingkungan fisik manusia dalam dimensi ruang. Salah satu multimedia interaktif pembelajaran yang diprediksikan dapat meningkatkan kemampuan membaca dan menulis anak adalah media pembelajaran yang terdapat dalam aplikasi telepon seluler bernama Hello English Kids: Learn English. Media Hello English Kids: Learn English di prediksikan dapat meningkatkan kemampuan membaca dan menulis anak karena media ini mengajarkan Bahasa Inggris kepada anak dengan cara yang menyenangkan, efektif dan dapat membangun fondasi kuat untuk pengembangan bahasa mereka sehingga dapat menarik perhatian, rasa keingintahuan, membangkitkan semangat serta menyenangkan bagi anak.

Kata kunci: membaca, menulis, multimedia
\end{abstract}

\section{PENDAHULUAN}

Pemberdayaan dan Kesejahteraan Keluarga (PKK) merupakan wadah membina keluarga bermasyarakat baik di perkotaan maupun di pedesaan yang dapat menghasilkan sinergi untuk keluarga sejahtera yang mandiri dengan meningkatkan mental spiritual perilaku hidup dengan menghayati dan mengamalkan Pancasila. Dapat dikembangkan lebih luas lagi dengan berbagai upaya atau usaha dan kegiatan, seperti meningkatkan pendidikan dan ketrampilan yang diperlukan, ikut mengupayakan dalam kehidupan 
bangsa serta meningkatkan pendapatan keluarga, meningkatkan kualitas adan kuantitas pangan keluarga, meningkatkan derajat kesehatan, kelestarian lingkungan hidup serta membiasakan hidup berencana dalam semua aspek kehidupan dan perencanaan ekonomi keluarga dengan membiasakan menabung. Dalam melakukan kegiatan tersebut perlu adanya pengelolaan PKK baik kegiatan pengorganisasian maupun pelaksaan programprogram, yang disesuaikan dengan situasi dan kondisi masyarakat.

Kelurahan Kampung Tengah merupakan suatu wilayah yang terletak di kecamatan Kramat Jati Jakarta Timur dengan jumlah penduduk sebesar 50.530 jiwa dan luas wilayah $2.03 \mathrm{Km} 2$, yang terdiri atas 7,070 KK (Kepala Keluarga). Kelurahan Kampung Tengah memiliki delapan puluh RT (Rukun Tetangga) dan sepuluh RW (Rukun Warga). Setiap RW memiliki kegiatan PKK, dari ke sepuluh RW ini pengabdian masyarakat yang akan dilaksanakan di PKK RW 10. Organisasi PKK di Kelurahan Kampung Tengah ini memiliki peranan dalam meningkatkan pemberdayaan wanita. Dalam melaksanakan kegiatan PKK ini memberikan kontribusi yang positif terhadap wanita sebagai ibu rumah tangga. Melalui PKK, wanita dapat mengaktualisasikan dirinya untuk aktif, selain perannya sebagai ibu rumah tangga.

Berdasarkan data yang diperoleh dari hasil observasi awal, menunjukkan bahwa kegiatan PKK di daerah ini lebih banyak diikuti oleh ibu-ibu rumah tangga. Karakteristik ibu-ibu anggota PKK di RW 10 Kelurahan Kampung Tengah dilihat dari kisaran umur, pendidikan formal dan pekerjaan. Kisaran umur antara 20-45 tahun. Jika dilihat dari kisaran umur tersebut, ibu-ibu masih merupakan usia yang produktif. Sebagian besar anggota PKK memiliki pendidikan Sekolah Menengah Atas dan dan sarjana. Hampir 90\% merupakan ibu rumah tangga biasa yang tidak memiliki pekerjaan lain yang menyita waktu. Berdasarkan hasil wawancara independen dan observasi awal di lapangan terhadap ibu-ibu PKK RW 10 Kelurahan Kampung Tengah, diperoleh permasalahan yaitu mereka kurang paham metode dan media pengajaran Bahasa Inggris yang efektif untuk mengajarkan membaca dan menulis pada anak-anak mereka di rumah.

Media dalam pembelajaran memiliki fungsi sebagai alat bantu untuk memperjelas pesan yang disampaikan guru. Media juga berfungsi untuk pembelajaran individual di mana kedudukan media sepenuhnya melayani kebutuhan belajar siswa. Menurut Dale Dalam Prasetyo (2007: 6)

"Secara umum media memiliki kegunaan yaitu: memperjelas pesan agar tidak terlalu verbalistis, mengatasi keterbatasan ruang, waktu tenaga dan daya indra, menimbulkan gairah belajar, interaksi lebih langsung antara murid dengan sumber belajar, memungkinkan anak belajar mandiri sesuai dengan bakat dan kemampuan visual, auditori \& kinestetiknya, memberi rangsangan yang sama, mempersamakan pengalaman \& menimbulkan persepsi yang sama".

Sehingga dapat disimpulkan media pembelajaran adalah seperangkat benda atau alat yang berfungsi dan digunakan sebagai fasilitator atau pelatih dalam komunikasi dan interaksi suatu proses pembelajaran dengan tujuan untuk mempermudah dan mempercepat proses penyampaian materi pembelajaran kepada peserta latih.

Proses pembelajaran khususnya untuk pembelajaran Bahasa Inggris akan lebih menyenangkan, tidak membosankan dan lebih mudah dipahami anak jika menggunakan media pembelajaran yang tepat yaitu media yang dapat menumbuhkan kemampuan 
membaca dan menulis anak. Media pembelajaran adalah sebuah alat yang berfungsi untuk menyampaikan pesan pembelajaran. Pembelajaran adalah sebuah proses komunikasi antara pembelajar, pengajar dan bahan ajar. Komunikasi tidak akan berjalan tanpa bantuan sarana penyampai pesan atau media. Menurut Bovee dalam Ena (2001: 2) Media pembelajaran interaktif adalah sebuah media yang dibuat guna memenuhi berbagai kebutuhan pembelajar bahasa asing pada waktu salah satu atau semua faktor yang mempengaruhi pemerolehan bahasa kedua ini sulit didapatkan.

Multimedia adalah salah satu sumber pengajaran atau media alternatif dalam pembelajaran Bahasa Inggris yang dapat memadukan dan mengaitkan unsur lingkungan fisik manusia dalam dimensi ruang. Menurut Suheri (2006: 3) multimedia adalah media yang menggabungkan dua unsur atau lebih media yang terdiri dari teks, grafis, gambar, foto, audio, video dan animasi secara terintegrasi.

Berdasarkan sejumlah pengamatan yang dilakukan, tim pelaksana memandang perlu memberikan kontribusi dalam hal pemberian masukan berupa pelatihan kepada ibu-ibu PKK RW 10 Kelurahan Kampung Tengah tentang pengenalan aplikasi multimedia Hello English Kids: Learn English sebagai media belajar bahasa Inggris. Sebagai langkah awal, tim pelaksana terlebih dahulu memberikan metode yang tepat untuk mengajarkan kosakata pada anak usia dini adalah melalui media. Hal ini bertujuan untuk memudahkan anak mengingat materi dan menghindarkan anak pada kebosanan. Media yang dipilih adalah media yang tidak memberatkan kedua belah pihak, yaitu pendidik dan anak didik. Media yang mudah dalam penyampaian dan murah akan harga merupakan media yang paling tepat. Media pembelajaran ini diperkenalkan sekaligus diajarkan kepada para ibu yang tergabung dalam PKK RW 10 Kelurahan Kampung Tengah tentang cara untuk menggunakan aplikasi multimedia pembelajaran Hello English Kids: Learn English sebagai media belajar bahasa Inggris.

\section{METODE PELAKSANAAN}

Pelaksanaan penerapan model pembelajaran multimedia dengan menggunakan aplikasi Hello English Kids bagi ibu PKK RW10 Kampung Tengah bertujuan untuk meningkatkan kemampuan orang tua dalam menggunakan multimedia untuk pembelajaran membaca dan menulis Bahasa Inggris. Pemakaian media akan mempermudah tugas orang tua dalam mengajarkan membaca dan menulis pada anak, sebab kosa kata yang diajarkan, diucapkan sekaligus diperlihatkan dalam bentuk tulisan, sehingga otak anak akan merekam bentuk tulisan dari suatu kata yang dipelajarinya. Selain itu, melalui kegiatan abdimas ini diharapkan dengan menggunakan aplikasi multimedia Hello English Kids mampu meningkatkan kemampuan membaca dan menulis permulaan bagi anak. Pemerolehan wawasan serta pengalaman belajar yang baru melalui kegiatan abdimas ini diharapkan juga memberikan wawasan kepada orang tua bahwa proses pembelajaran membaca dan menulis anak harus senantiasa ditingkatkan dengan cara menciptakan suasana pembelajaran yang kondusif dan menyenangkan salah satunya dengan menggunakan aplikasi multimedia.

Metode yang dipilih dalam melaksanakan kegiatan abdimas ini adalah pelatihan terutama kepada para Ibu-ibu PKK RW 10 Kampung Tengah di Jakarta Timur. Pemberian 
pelatihan diutamakan bagi Ibu-ibu PKK karena mereka memiliki keterbatasan pengetahuan dan ketrampilan mengenai media pembelajaran yang efektif untuk mengajarkan membaca dan menulis pada anak-anak mereka di rumah. Untuk mencapai tujuan yang telah ditetapkan, maka kegiatan pengabdian kepada masyarakat ini dilakukan dengan menggunakan langkah-langkah sebagai berikut: pertama, tim pengabdian masyarakat melakukan penyemaian informasi, berupa landasan teoretis tentang aplikasi multimedia yang dapat digunakan dalam proses pembelajaran. Kedua, pemberian model berupa contoh-contoh aplikasi multimedia yang dapat digunakan dapat digunakan dalam pembelajaran di rumah, salah satunya adalah aplikasi multimedia Hello English Kids. Ketiga, mempraktikkan aplikasi multimedia Hello English Kids dalam proses mengajarkan kosa kata untuk membaca dan menulis Bahasa Inggris kepada anak. Keempat, kegiatan pendampingan (monitoring) dilaksanakan dengan cara mengumpulkan para ibu beserta anak- anak, kemudian memberikan repetition drill, dan yang terakhir adalah memonitor kegiatan mereka dalam mengaplikasikan multimedia Hello English Kids.

Pemberian pelatihan dilakukan oleh tim pengabdian masyarakat. Sementara itu, Ibuibu PKK RW 10 bertugas menyediakan sarana prasarana demi lancarnya kegiatan pelatihan seperti sumber listrik, tempat, meja dan kursi. Pelatihan dilaksanakan dengan pendekatan andragogi. Metode pembelajaran lebih banyak demonstrasi, tanya jawab dan praktik. Materi pelatihan disajikan dengan lebih banyak praktik daripada teori, dengan rasio perbandingan $30 \%$ teori dan $70 \%$ praktik.

Keberhasilan program pelaksanaan pelatihan ini dievaluasi dengan pengamatan langsung (observation). Adapun indikator keberhasilan dari kegiatan ini adalah bertambahnya pengetahuan dan keterampilan orang tua dalam menggunakan aplikasi multimedia Hello English Kids dalam pembelajaran membaca dan menulis Bahasa Inggris.

\section{HASIL DAN PEMBAHASAN}

Membaca dan menulis adalah salah satu aspek keterampilan berbahasa yang dipelajari di sekolah dasar dengan tujuan agar para peserta didik mengerti maksud yang terkandung di dalam bacaan sehingga mampu memahami isi bacaan dengan baik dan benar. Membaca dan menulis permulaan merupakan dua aspek kemampuan berbahasa yang saling berkaitan dan tidak terpisahkan. Pada saat guru memperkenalkan cara menulis, maka peserta didik akan membaca tulisannya. Menulis sebagai salah satu aspek kemampuan berbahasa harus mampu dikuasai oleh peserta didik. Kegiatan membaca dan menulis merupakan kegiatan yang unik dan rumit, sehingga seseorang tidak dapat melakukan hal tersebut tanpa mempelajarinya, terutama anak usia sekolah dasar yang baru mengenal huruf atau kata- kata. Salah satu metode pembelajaran yang dianggap mampu memberikan suasana belajar interaktif melalui penerapan metode pembelajaran dengan menggunakan aplikasi multimedia Hello English Kids pada pembelajaran membaca dan menulis bahasa Inggris.

Proses pembelajaran pada hakikatnya adalah proses komunikasi, penyampaian pesan dari pengantar ke penerima. Pesan berupa isi materi pelajaran yang dituangkan ke dalam simbol-simbol komunikasi baik verbal (kata-kata dan tulisan) maupun non verbal, 
proses ini dinamakan encoding. Penafsiran simbol- simbol komunikasi tersebut oleh siswa dinamakan decoding. Dalam penafsiran tersebut ada kalanya berhasil dan adakalanya tidak berhasil atau gagal. Dengan kata lain dapat dikatakan kegagalan/ tidak berhasil dalam memahami apa yang didengar, dibaca, dilihat atau diamati. Kegagalan/tidak berhasil itu disebabkan oleh gangguan yang menjadi penghambat komunikasi yang dalam proses komunikasi dikenal dengan istilah barriers atau noise. Semakin banyak verbalisme semakin abstrak pemahaman yang diterima. Kegunaan multimedia interaktif adalah untuk mengurangi penyampaian pesan yang bersifat verbalistis serta untuk mengatasi keterbatasan ruang waktu dan tenaga sehingga menimbulkan gairah, interaksi anak dengan sumber belajar serta memungkinkan anak dapat belajar secara mandiri.

Penggunaan media dalam pembelajaran dapat mempermudah anak dalam memperoleh pengalaman belajar dari sesuatu yang abstrak menjadi lebih konkret. Media pembelajaran berbasis multimedia interaktif yang memadukan teks, grafik, video serta audio yang dapat meningkatkan semangat anak dalam mengenal pelajaran khususnya dalam pembelajaran membaca dan menulis Bahasa Inggris. Dengan adanya media pembelajaran berbasis multimedia interaktif ini, maka proses pembelajaran lebih bervariasi dibandingkan sebelumnya yang hanya menggunakan metode ceramah dan tanya jawab. Orang tua pun bisa mengajari anak dengan menggunakan media dalam proses pembelajaran yang memudahkan anak untuk lebih paham dengan cepat. Salah satu media yang dapat digunakan oleh orang tua dalam mengajar membaca dan menulis Bahasa Inggris adalah aplikasi multimedia Hello English Kids.

Aplikasi multimedia Hello English Kids memang digunakan untuk mengembangkan kecerdasan linguistik, terutama dalam hal memperkaya kosakata. Akan tetapi, pada faktanya Hello English Kids dapat digunakan untuk melatih empat keterampilan berbahasa termasuk di dalamnya menyimak, berbicara, membaca, dan menulis. Keterampilan menyimak dapat dilatih ketika pengguna mendengarkan audio yang berisi definisi atau istilah tertentu, berbicara terjadi ketika pengguna mengulang kembali katakata yang telah dilafalkan melalui flashcard, membaca dilakukan ketika pengguna memainkan mode stories dan nursery rhymes dengan membaca tulisan yang terdapat dalam cerita dan bernyanyi sesuai dengan ejaan, dan menulis dimanfaatkan ketika menggunakan mode writing skills melalui praktik mengetik jawaban dengan ejaan yang benar.

Kegiatan Pengabdian Masyarakat ini dilaksanakan dalam dua tahap, yaitu tahap pelatihan dan monitoring. Kegiatan pelatihan dilaksanakan di Posyandu Lestari 1 Kampung Tengah. Pelatihan pertama ini memberikan teori dan mengenalkan metode pembelajaran dengan menggunakan multimedia kepada para ibu PKK. Tim pengabdian masyarakat mengajarkan kepada peserta bagaimana menerapkan metode pembelajaran interaktif dengan menggunakan aplikasi multimedia Hello English Kids ini pada anak. Setelah memahami penjelasan dari Tim, para ibu mulai menggunakan aplikasi multimedia Hello English Kids dengan bantuan dan panduan oleh tim pengabdian masyarakat. Di tahap ini para ibu mengetahui dan mempelajari bahwa dengan menggunakan aplikasi multimedia Hello English Kids Orang tua pun bisa mengajari anak 
dengan menggunakan media dalam proses pembelajaran yang memudahkan anak untuk lebih paham dengan cepat.

Kegiatan monitoring dilakukan dengan cara tim mendatangi Posyandu Lestari 1 Kampung Tengah, tempat para ibu berkumpul dengan anak guna mempraktikkan ilmu pelatihan hari pertama. Tim pengabdian masyarakat mengamati situasi yang terjadi dan interaksi antara ibu dan anak dalam proses mengajarkan membaca dan menulis berbahasa Inggris kepada anak. Di dalam proses pembelajaran ini, pertama-tama para ibu membuka aplikasi Hello English Kids melalui telepon seluler, kemudian membuka mode writing skills untuk melatih anak menulis kata dalam Bahasa Inggris sedangkan untuk melatih membaca menggunakan mode nursery rhymes and stories. Penggunaan aplikasi ini juga disertai pendampingan oleh ibu, pendampingan ini membantu ibu dalam memahami sejauh mana perkembangan pembelajaran Bahasa Inggris anak. Latihan menulis dan membaca dengan menggunakan aplikasi Hello English Kids dapat digunakan sebagai bahan pendamping pembelajaran Bahasa Inggris di rumah. Hasil dari penggunaan aplikasi Hello English Kids ini, anak mampu mengucapkan kata-kata berbahasa Inggris dengan benar dan kemampuan mereka mengingat tulisan terasah.

Pembelajaran dengan menggunakan model pembelajaran multimedia aplikasi Hello English Kids diharapkan dapat memberikan hasil dan manfaat pembelajaran yang diwujudkan ke dalam luaran (output) pembelajaran agar dapat digunakan khalayak ramai, dalam hal ini secara khusus terhadap dunia pendidikan dan pengajaran. Adapun luaran yang dapat dihasilkan dari kegiatan pembelajaran ini antara lain berupa buku ajar seperti penyusunan modul (workbook) untuk orang tua agar dapat memahami materi ajar secara lebih detail. Penyusunan modul dilakukan dalam rangka pemberian umpan balik tim pelaksana kepada orang tua terhadap kegiatan pembelajaran yang dilakukan dengan harapan dapat meningkatkan pemahaman kosakata untuk kemampuan membaca dan menulis anak.

\section{Gambar 1 Aplikasi Hello English Kids}
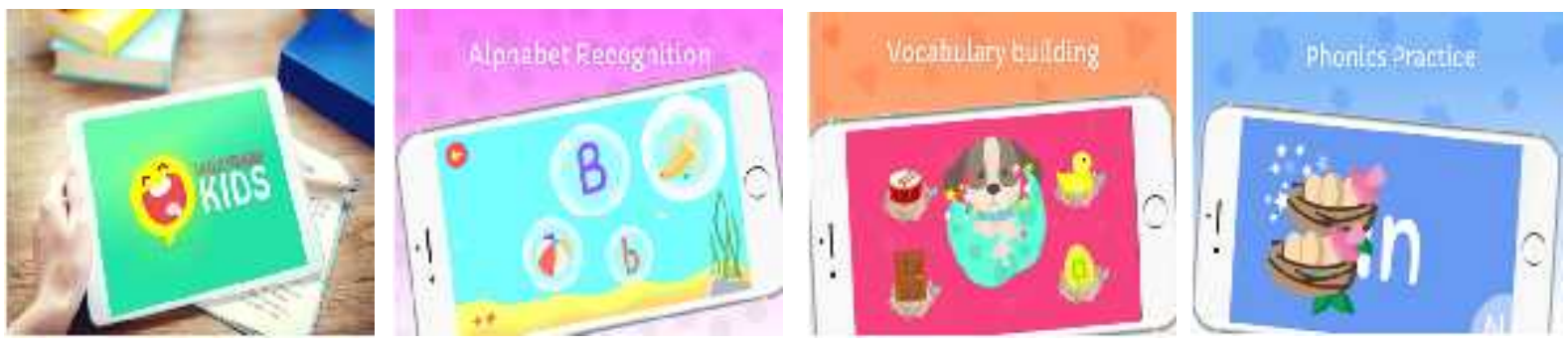

Gambar 2 Kegiatan Pelatihan
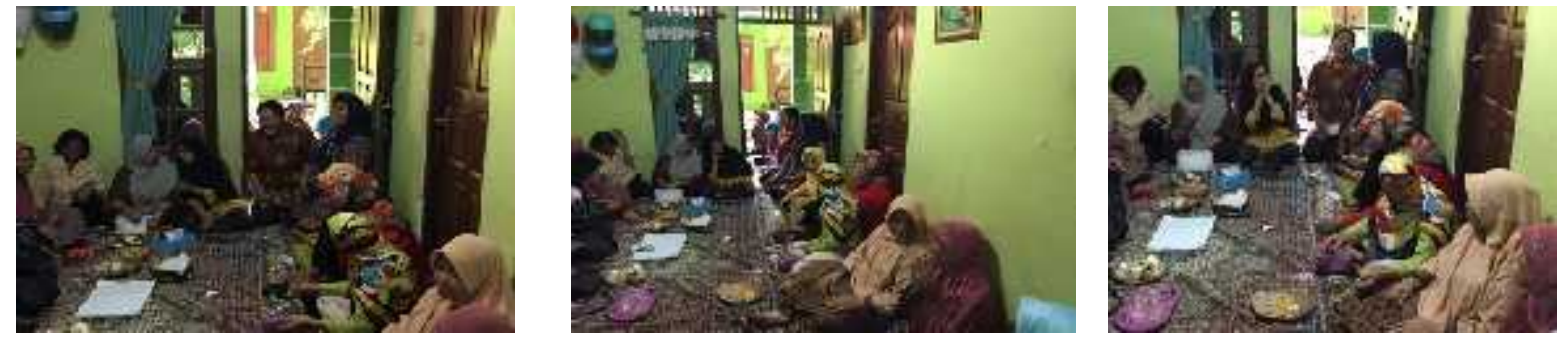


\section{SIMPULAN}

Dari hasil pelaksanaan kegiatan pengabdian kepada masyarakat, diberikan beberapa kesimpulan yaitu aplikasi Hello English Kids merupakan salah satu media yang tepat untuk digunakan dalam mengajarkan Bahasa Inggris, terutama membaca dan menulis kepada anak dengan cara yang menyenangkan dan mudah serta pemakaian media akan mempermudah tugas orang tua dalam mengajar membaca dan menulis, sebab kosa kata yang diajarkan, diucapkan sekaligus diperlihatkan dalam bentuk tulisan, sehingga otak anak akan merekam bentuk tulisan dari suatu kata yang dipelajarinya. Anak akan merasa senang dan antusias karena mereka belajar bahasa Inggris dan sekaligus bermain dalam waktu yang bersamaan.

\section{UCAPAN TERIMA KASIH}

Ucapan terima kasih kami sampaikan kepada Lembaga Penelitian dan Pengabdian Masyarakat (LPPM) Universitas Indraprasta PGRI atas pemberian dana hibah bagi kegiatan yang kami laksanakan.

\section{DAFTAR RUJUKAN}

Ena, Ouda, T. 2001. Membuat Media Pembelajaran Interaktif dengan Piranti Lunak Presentasi. Yogyakarta: Indonesian Language and Culture Intensive Course Universiatas Sanata Dharma.

Prasetyo, Sigit. 2007. Pengembangan Pembelajaran dengan Menggunakan Multimedia Interaktif untuk Pembelajaran yang Berkualitas. Semarang: UNNES.

Suheri, Agus. 2006. Animasi Multimedia Pembelajaran, Jurnal Media Teknologi, Vol. 2, No. 1. Cianjur: Universitas Suryakencana. 
132 J-Abdipamas, Vol. 4, No. 2, Oktober, 2020 